\title{
Ranking uncertainties in atmospheric dispersion modelling following the accidental release of radioactive material
}

\author{
S.J. Leadbetter ${ }^{1, *}$, S. Andronopoulos ${ }^{2}$, P. Bedwell ${ }^{3}$, K. Chevalier-Jabet ${ }^{4}$, G. Geertsema ${ }^{5}$, F. Gering ${ }^{6}$, \\ T. Hamburger ${ }^{6}$, A.R. Jones ${ }^{1}$, H. Klein ${ }^{7}$, I. Korsakissok ${ }^{4}$, A. Mathieu ${ }^{4}$, T. Pázmándi ${ }^{8}$, R. Périllat ${ }^{4,9}$, \\ Cs. Rudas ${ }^{8}$, A. Sogachev ${ }^{10}$, P. Szántó ${ }^{8}$, J.M. Tomas ${ }^{11}$, C. Twenhöfel ${ }^{11}$, H. de Vries ${ }^{5}$ and J. Wellings ${ }^{3}$ \\ 1 Met Office, Exeter, UK. \\ 2 EEAE/NCSRD-Greek Atomic Energy Commission)/National Center for Scientific Research "Demokritos", Agia Paraskevi, Greece. \\ ${ }^{3}$ PHE-Public Health England, Didcot, UK. \\ ${ }^{4}$ IRSN - Institute for Radiation Protection and Nuclear Safety, Fontenay-aux-Roses, France. \\ ${ }^{5}$ KNMI-Royal Netherlands Meteorological Institute, De Bilt, The Netherlands. \\ ${ }^{6}$ BfS - Federal Office for Radiation Protection, Neuherberg, Germany. \\ 7 NMI-The Norwegian Meteorological Institute, Oslo, Norway. \\ ${ }^{8}$ EK - Centre for Energy Research, Budapest, Hungary. \\ 9 PHIMECA Engineering, Clermont-Ferrand, France. \\ ${ }^{10}$ DTU Wind Energy, Roskilde, Denmark. \\ 11 RIVM - National Institute for Public Health and the Environment, Bilthoven, The Netherlands.
}

\begin{abstract}
During the pre-release and early phase of an accidental release of radionuclides into the atmosphere there are few or no measurements, and dispersion models are used to assess the consequences and assist in determining appropriate countermeasures. However, uncertainties are high during this early phase and it is important to characterise these uncertainties and, if possible, include them in any dispersion modelling. In this paper we examine three sources of uncertainty in dispersion modelling; uncertainty in the source term, uncertainty in the meteorological information used to drive the dispersion model and intrinsic uncertainty within the dispersion model. We also explore the possibility of ranking these uncertainties dependent on their impact on the dispersion model outputs.
\end{abstract}

Keywords: uncertainty / atmospheric dispersion model / source terms / ensemble simulation / CONFIDENCE

\section{Introduction}

In the event of an accidental release of radionuclides into the atmosphere, dispersion models would be used (in conjunction with dose models) to evaluate the consequences and to assist in determining appropriate countermeasures. In order to model the consequences, the dispersion model requires information about the type, quantity, timing and physical characteristics of the release (referred to as the source term) as well as details of the meteorological conditions during the period of release and transport of pollutants. The accuracy of the dispersion predictions (i.e., the difference between the model-calculated and the observed values of variables like concentration in air or deposition on ground of radioactive material) clearly depends (among other factors) on the

\footnotetext{
*Corresponding author: susan.leadbetter@metoffice.gov.uk
}

accuracy of these inputs (i.e., how close these inputs are to their true values). Increasingly there is also pressure (e.g. from decision makers, the scientific community) to provide information on the uncertainty of the dispersion and deposition forecasts.

There are several sources of uncertainty in the dispersion model prediction including those related to the source term information and the driving meteorology as well as physical parametrisations and numerical approximations made in the dispersion model. A useful discussion on the types on uncertainties in dispersion models is given by Rao (2005). In this paper we consider uncertainties that are most prevalent in the early phase of a nuclear accident. The sources of uncertainty are not completely independent. For example, the uncertainty in the timing of the release is linked to the variability and the uncertainty in the meteorological information over the same period. However, as the estimation of uncertainties in the three categories is approached differently it 
is convenient to examine them separately and a discussion of each can be found in the next three sections. Some comments on combining uncertainties and their relative importance are given at the end of the paper.

\section{Meteorological uncertainty}

Meteorological information for dispersion models is usually obtained from Numerical Weather Prediction (NWP) models as 3D or 4D fields of variables such as wind speed and direction, boundary layer height and precipitation. Most dispersion models used in emergency response take information from a single NWP model. However, the atmosphere is a chaotic system meaning that small deviations from the initial conditions can grow quickly. Meteorological modellers typically overcome this by running multiple model integrations where each model integration starts from a perturbed initial state and uses perturbed model physics to represent uncertainty in the atmospheric state and its evolution (Fig. 1) (see Leadbetter et al., 2018 for more details). These are known as "ensemble" models and were first used for weather forecasting in the 1990s. They have been used as inputs to dispersion models in research and post event analysis since the late 1990s (Straume et al., 1998).

Ensemble meteorological systems are computationally expensive; so an alternative method for generating a meteorological ensemble is through the use of successive forecasts from a single meteorological model. These ensembles are called time-lagged ensembles and can be used as input to a dispersion model ensemble (e.g. Geertsema et al., 2019).

Meteorological ensembles have been developed and improved for many years and now demonstrate a good ability to represent the uncertainty in large scale atmospheric variables such as the height of the $500 \mathrm{hPa}$ pressure level (Haiden et al., 2016). However, for near-surface variables, such as those of interest to dispersion modellers, many ensembles show a tendency to be under-dispersive. Studies by Haywood (2008) and Girard et al. (2016) show that wind speed, wind direction and precipitation uncertainties are important for surface releases and a study by Hamburger and Gering (2017) showed that in a stable atmosphere, dispersion model predictions can be very sensitive to small perturbations in atmospheric stability. Furthermore, Descamps et al. (2015) show that Météo-France and the European Centre for Mediumrange Weather Forecasting's global ensemble models are under-dispersive in their prediction of $10 \mathrm{~m}$ wind-speed and 24-hour precipitation over Europe. Whilst wind speed and precipitation are of interest to weather forecasters, representing the uncertainty in the meteorological parameters important to dispersion models is not prioritised by the developers of meteorological ensembles.

To improve the representation of uncertainty in nearsurface variables and over short time-periods many national weather centres have developed limited area ensembles focussing on uncertainty within the first 48-hours of the forecast (e.g. Tennant, 2015). A study by Flowerdew (2012) demonstrated that these higher resolution ensembles are more reliable at predicting precipitation than lower resolution ensembles.

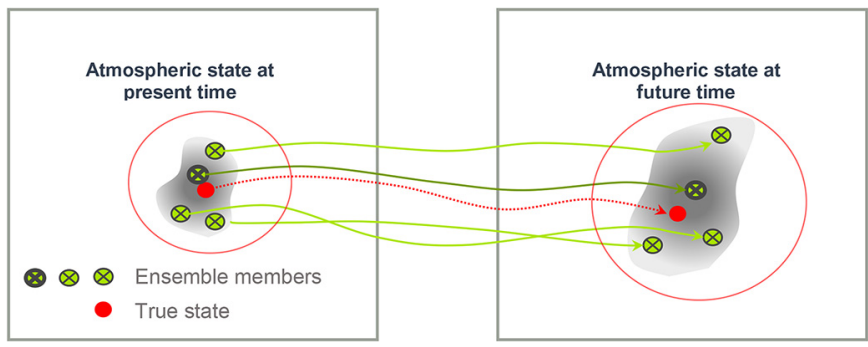

Fig. 1. Schematic of an ensemble meteorological forecast. The red circles and line represent the true state and the bold black member represents the control or "deterministic" forecast.

To use the meteorological information provided by NWP models, most dispersion models include a meteorological preprocessor. This pre-processor may be a separate model, or it may be integrated into the dispersion model and is typically used to interpolate meteorological information (in space and time) and compute meteorological variables not available in the NWP data set. Uncertainties in the meteorological preprocessor arise from the choice of interpolation scheme and the method of calculation of missing meteorological variables (Andronopoulos et al., 2018).

To mitigate against these additional uncertainties and to include data from meteorological stations in the period between the last meteorological model run and the dispersion model run some dispersion models assimilate surface meteorological observations. For example, Davakis et al. (2007) demonstrated improvements in the simulation of the European Tracer release EXperiment (ETEX) when meteorological observations were assimilated.

\section{Source term uncertainties}

To correctly model the dispersion of a release of radionuclides information about source parameters such as the timing and duration of release, isotopic composition, emitted amount (per radionuclide), physiochemical form and height of the release is required. Source terms are usually estimated using one of two methods, both of which can also be used to estimate the uncertainty:

1 Modelling of the reactor physics and potential failure mechanisms. The source term is estimated using tools that consider reactor physics and knowledge of the initial state of the facility, such as the severe accident code ASTEC (Accident Source Term Evaluation Code) (Chatelard et al., 2014), or more simplified approaches such as tools used in case of emergency. Uncertainties in the reactor physics method can be accounted for by assuming uncertainties on different parts of the process, for example the size and location of a break and the behaviour of iodine in its liquid and gaseous forms. An evaluation of this type was carried out as part of the FASTNET (FAST Nuclear Emergency Tools) project (Chevalier-Jabet, 2019a, 2019b). Results from this project were used in the REM (Radiological Ensemble Modelling) case study (Korsakissok et al., 2020). However, there are uncertainties that cannot be accounted for using this method due to a lack of information or human errors; 
Table 1. Uncertainty categories.

\begin{tabular}{|c|c|c|}
\hline & Examples & Description \\
\hline Category 1 & $\begin{array}{l}\text { Release rate } \\
\text { Wind direction }\end{array}$ & $\begin{array}{l}\text { These are the most influential parameters. The amount or rate of } \\
\text { material released often relies on measurements that are not } \\
\text { available in the early phase of an incident and work by Astrup and } \\
\text { Mikkelsen (2010) has shown that observed wind directions can } \\
\text { differ from the NWP wind directions by up to } 25^{\circ} \text { in flat terrain } \\
\text { and more in more complex terrain. }\end{array}$ \\
\hline Category 2 & $\begin{array}{l}\text { Plume rise or release height } \\
\text { Wind speed } \\
\text { Release timing }\end{array}$ & $\begin{array}{l}\text { These are parameters that are often, but not always, influential. For } \\
\text { example, the release timing could be influential if the timing of the } \\
\text { release coincides with a change of wind direction or a precipitation } \\
\text { event, otherwise it may only impact the time until the plume } \\
\text { arrives and will have little impact on quantities integrated over a } \\
\text { time period. }\end{array}$ \\
\hline Category 3 & $\begin{array}{l}\text { Precipitation } \\
\text { Wet and dry scavenging parameters } \\
\text { Particle size distribution }\end{array}$ & $\begin{array}{l}\text { These are parameters that are not relevant to all scenarios but can } \\
\text { be very influential in some circumstances. When precipitation does } \\
\text { occur, it can have a big impact on the amount of material } \\
\text { deposited on the ground. In addition, the location of rainfall } \\
\text { generated by convection can be difficult to predict accurately. }\end{array}$ \\
\hline Category 4 & $\begin{array}{l}\text { Atmospheric stability } \\
\text { Boundary layer depth or mixing height } \\
\text { Vertical and horizontal diffusion parameters }\end{array}$ & Parameters that only have a moderate influence. \\
\hline Category 5 & $\begin{array}{l}\text { Resolution of the terrain } \\
\text { Surface roughness Model time step } \\
\text { Model grid cell size Vertical source profile } \\
\text { Ambient temperature }\end{array}$ & $\begin{array}{l}\text { These parameters were not found to be particularly influential in } \\
\text { the reviewed studies but could be influential in some } \\
\text { circumstances. }\end{array}$ \\
\hline
\end{tabular}

2 Coupling dispersion modelling and measurements in the environment. In the early phase under investigation in this project this is not feasible. However, experience from historic events can provide valuable insights into uncertainties by using a coupling approach in which the source term is estimated by combining environmental measurements with dispersion model predictions. This may be done through semi-manual reverse techniques (e.g. Katata et al., 2015) or automatic inverse modelling methods (e.g. Saunier et al., 2013) that use mathematical methods to minimize the discrepancy between dispersion results and radiological measurements. Uncertainties in this method can be estimated by considering different measurement data and/or by using ensemble dispersion model output. In Korsakissok et al. (2020) nine source terms were selected from the literature to represent uncertainty in the Fukushima accident source term. The source terms were constructed using different meteorological data, different dispersion models and different measurement data.

Estimation of source term uncertainties and their use in modelling the dispersion of radioactive material is a relatively new area of research so there are limited examples of its use.

\section{Atmospheric dispersion model uncertainties}

The limitations of dispersion models and their input data mean that some processes cannot be resolved explicitly and need to be parameterised. Examples of such processes are turbulent diffusion schemes and wet and dry deposition. A limited number of studies have examined the impact of perturbing these parametrisations on the dispersion model predictions (e.g. Leadbetter et al., 2015; Girard et al., 2016). Parameter ranges are determined from literature reviews and/ or expert elicitation and the results evaluated by comparing model outputs to measurements or other model outputs.

Turbulent diffusion is typically represented by applying deviations to the movement of the plume relative to the mean wind. Different parametrisations are used according to the type of dispersion model: Gaussian, Eulerian or Lagrangian. In a Gaussian model turbulence is usually represented as the standard deviation of the cross-wind, along-wind and vertical motion whereas in a Lagrangian or Eulerian model the turbulence is usually represented by a diffusivity parameter, $\mathrm{K}$. The magnitude of these parameters varies according to the meteorological state, for example as a function of the atmospheric stability, and different values may be applied above and below the top of the boundary layer. A full description of the recommended ranges and methods used to determine these can be found in Bedwell et al. (2018).

Wet and dry depositions are often described by depletion equations because few off-line dispersion models resolve incloud micro-physical properties or the interaction between particles and different surface types (such as buildings and plants). Parametrisations for wet deposition typically consider different types of precipitation (rain or snow or a mixture) and different rain rates. Parametrisations for dry deposition generally consider different particle properties and some also consider different surface types. Several studies investigated the impact of wet scavenging coefficients on the predictions of 
deposits following the Fukushima Dai-ichi nuclear power plant accident. No consensus was reached on the best scavenging coefficients suggesting that a range of coefficients should be considered as part of an ensemble dispersion model (see for example, Leadbetter et al., 2015; Quérel et al., 2015).

\section{Ranking uncertainties}

The uncertainties described above could simply be combined into a huge ensemble. However, this is computationally expensive and may not produce useful results on the short timescales needed in the early phase of an incident. It is therefore useful to consider whether some uncertainties are likely to have a greater or lesser impact and if some uncertainties will only apply to some situations.

Wellings et al. (2018) conducted a literature review to investigate the sensitivity of the dispersion model outputs of air concentration and deposition to uncertainty in the input data and internal parameterisations. They concluded that it was not possible to determine a quantitative ranking of the uncertainties due to the wide range of models, parameters and scenarios presented in the literature. Instead, they grouped uncertainties into seven categories according to the influence their uncertainties might have on modelling results. Parameters in categories 6 and 7 are those parameters that were determined to not be relevant to modelling in the CONFIDENCE project or to not be influential in the modelling output in the studies in the literature review. A description of the other categories and the parameters in them is given in Table 1.

\section{Summary}

In this paper the sources of uncertainty when modelling the dispersion of an accidental release of radioactive material are discussed. The uncertainties have been separated into three sources, meteorological data, source term and dispersion model due to the different methods of assessing the uncertainty. Uncertainties in the meteorological data are usually represented using data from an ensemble of meteorological models. Uncertainties in the source term may be represented by generating an ensemble of source terms by considering processes in the accident sequence or by using different meteorological models and radiological observations to calculate the source term using reverse or inverse methods. Uncertainties in dispersion modelling are usually estimated from literature reviews and expert elicitation. All these uncertainties can be propagated into an ensemble dispersion modelling system in order to infer their effect on outputs such as dose, air concentration and deposition. It is also useful to consider the most influential sources of uncertainties so that these can be prioritised in the construction of a dispersion ensemble.

Acknowledgement. The work described in this paper was conducted within the CONFIDENCE project which was part of the CONCERT project. This project has received funding from the Euratom research and training programme 20142018 under grant agreement No. 662287.

The authors would like to thank S. Fougerolle and F. Stephani for their contribution on source term uncertainties and Claire Witham for her helpful comments and suggestions. The authors would also like to thank Linda Walsh for her review of this manuscript.

Disclaimer (Art. 29.5 GA). This publication reflects only the author's view. Responsibility for the information and views expressed therein lies entirely with the authors. The European Commission is not responsible for any use that may be made of the information it contains.

\section{References}

Andronopoulos S, Geertsema G, Klein H, de Vries H. 2018. Guidelines ranking uncertainties for atmospheric dispersion, D9.1.2 using meteorological measurements to reduce uncertainty. CONCERT Deliverable D9.1. Available from https://concerth2020.eu/en/Publications

Astrup P, Mikkelsen TK. 2010. Comparison of NWP prognosis and local monitoring data from NPPs. Radioprotection 45(5): 97-111. https://doi.org/10.1051/radiopro/2010019.

Bedwell P, Wellings J, Leadbetter S, Tomas J, Andronopoulos S, Korsakissok I, Périllat R, Mathieu A, Geertsema G, Klein H, de Vries H, Hamburger T, Pázmándi T, Rudas Cs, Sogachev A, Szántó P. 2018. Guidelines ranking uncertainties for atmospheric dispersion. D9.1.4 Guidelines detailing the range and distribution of atmospheric dispersion model input parameter uncertainties. CONCERT Deliverable D9.1. Available from https://concerth2020.eu/en/Publications.

Chatelard P, Reinke N, Arndt S, Belon S, Cantrel L, Carenini L, Chevalier-Jabet K, Cousin F, Eckel J, Jacq F, Marchetto C, Mun C, Piar L. 2014. ASTEC V2 severe accident integral code main features, current V2.0 modelling status, perspectives. Nucl. Eng. Des. 272: 119-135.

Chevalier-Jabet K. 2019a. Source term prediction in case of a severe nuclear accident. In: 5th NERIS Workshop, 3-5 April 2019, Roskilde, Denmark.

Chevalier-Jabet K. 2019b. Design and use of Bayesian networks for the diagnosis/prognosis of severe nuclear accidents, EU program for research and innovation H2020 - FAST Nuclear Emergency Tools (FASTNET) project. Report FASTNET-DATA-D2.3.

Davakis E, Andronopoulos S, Kovalets I, Gounaris N, Bartzis JG, Nychas SG. 2007. Data assimilation in meteorological preprocessors: Effects on atmospheric dispersion simulations. Atmos. Environ. 41(14): 2917-2932. https://doi.org/10.1016/j.atmos env.2006.12.031.

Descamps L, Labadie C, Joly A, Bazile E, Arbogast P, Cébron P. 2015. PEARP, the Météo France short-range ensemble prediction system. Q. J. Royal Meteorol. Soc. 141(690): 1671-1685. https:// doi.org/10.1002/qj.2469.

Flowerdew. 2012. Calibration and combination of medium-range ensemble precipitation forecasts. Met Office Forecasting Technical Report 567.

Geertsema G, De Vries H, Sheele R. 2019. High resolution meteorological ensemble data for CONFIDENCE research on uncertainties in atmospheric dispersion in the (pre-)release phase of a nuclear accident. In: 19th International Conference on Harmonisation within Atmospheric Dispersion Modelling for Regulatory Purposes, Bruges, Belgium.

Girard S, Mallet V, Korsakissok I, Mathieu A. 2016. Emulation and sobol sensitivity analysis of an atmospheric dispersion model applied to the Fukushima nuclear accident. J. Geophys. Res.: Atmos. 121(7): 3484-3496. https://doi.org/10.1002/2015JD023993. 
Haiden T, Janousek M, Bidlot J, Ferranti L, Prates F, Vitart F, Bauer P, Richardson DS. 2016. Evaluation of ECMWF forecasts, including the 2016 resolution upgrade. Available from https://www.ecmwf. $\mathrm{int} /$ sites/default/files/elibrary/2016/16924-evaluation-ecmwf-fore castsincluding-2016-resolution-upgrade.pdf.

Hamburger T, Gering F. 2017. Data assimilation and uncertainty handling in food chain and dose models based on model ensembles. In: CONFIDENCE Ensembles Workshop, Paris.

Haywood S.M. 2008. Key sources of imprecision in radiological emergency assessments. J. Radiol. Protect. 28(2): 169-183.

Katata G, Chino M, Kobayashi T, Terada H, Ota M, Nagai H, Kajino M, Draxler R, Hort MC, Malo A, Torii T, Sanada Y. 2015. Detailed source term estimation of the atmospheric release for the Fukushima Daiichi Nuclear Power Station accident by coupling simulations of an atmospheric dispersion model with an improved deposition scheme and oceanic dispersion model. Atmos. Chem. Phys. 15(2): 1029-1070.

Korsakissok I, Périllat R, Andronopoulos S, Bedwell P, Berge E, Charnock T, Geertsema G, Gering F, Hamburger T, Klein H, Leadbetter S, Lind O-C, Pazmandi T, Rudas Cs, Salbu B, Sogachev A, Syed N, Tomas J, Ulimoen M, De Vries H, Wellings J. 2020. Uncertainty propagation in atmospheric dispersion models for radiological emergencies in the pre and early release phase: Summary of case studies. Radioprotection 55(HS1). https://doi.org/10.1051/radiopro/2020013.

Leadbetter SJ, Hort MC, Jones AR, Webster HN, Draxler RR. 2015. Sensitivity of the modelled deposition of Caesium-137 from the Fukushima Dai-ichi nuclear power plant to the wet deposition parameterisation in NAME. J. Environ. Radioact. 139: 200-211. https://doi.org/10.1016/j.jenvrad.2014.03.018.
Leadbetter S, Andronopuulos S, Bedwell P, Geertsema G, Jones AR, Korsaikssok I, Thomas J, de Vries H. 2018. Guidelines ranking uncertainties for atmospheric dispersion, D9.1.1 using ensemble meteorological forecasts to represent meteorological uncertainty in dispersion models. CONCERT Deliverable D9.1. Available from https://concert-h2020.eu/en/Publications.

Quérel A, Roustan Y, Quélo D, Benoit J-P. 2015. Hints to discriminate the choice of wet deposition models applied to an accidental radioactive release. Int. J. Environ. Pollution 58(4). https://doi. org/10.1504/IJEP2015.077457.

Rao KS. 2005. Uncertainty analysis in atmospheric dispersion modeling. Pure Appl. Geophys. 162: 1893-1917. https://doi.org/ 10.1007/s00024-005-2697-4.

Saunier O, Mathieu A, Didier D, Tombette M, Quélo D, Winiarek V, Bocquet M. 2013. An inverse modelling method to assess the source term of the Fukushima Nuclear Power Plant accident using gamma dose rate observations. Atmos. Chem. Phys. 13(22): 11403-11421. https://doi.org/10.5194/acp-13-11403-2013.

Straume AG, Koffi EN, Nodop K. 1998. Dispersion modelling using ensemble forecasts compared to ETEX measurements. J. Appl. Meteorol. 37(11): 1444-1456.

Tennant W. 2015. Improving initial condition perturbations for MOGREPS-UK. Q. J. Royal Meteorol. Soc. 141(691): 2324 2336. https://doi.org/10.1002/qj.2524.

Wellings J, Bedwell P, Leadbetter S, Tomas J, Andronopoulos S, Korsakissok I, Périllat R, Mathieu A, Geertsema G, de Vries H, Hamburger T, Gering F, Pázmándi T, Szánto P, Rudas Cs, Sogachev A, Davis N, Twenhofel C. 2018. Guidelines ranking uncertainties for atmospheric dispersion, D9.1.5 Guidelines for ranking uncertainties in atmospheric dispersion. CONCERT Deliverable D9.1. Available from https://concert-h2020.eu/en/Publications.

Cite this article as: Leadbetter SJ, Andronopoulos S, Bedwell P, Chevalier-Jabet K, Geertsema G, Gering F, Hamburger T, Jones AR, Klein H, Korsakissok I, Mathieu A, Pázmándi T, Périllat R, Rudas Cs, Sogachev A, Szántó P, Tomas JM, Twenhöfel C, de Vries H, Wellings J. 2020. Ranking uncertainties in atmospheric dispersion modelling following the accidental release of radioactive material. Radioprotection 55(HS1): S51-S55 